\title{
ENTRE A SUBORDINAÇÃO E A AGÊNCIA: UMA ANÁLISE DA GEOSSOCIABILIDADE FEMININA A PARTIR DO FILME UMA LINDA MULHER
}

\author{
R. L. ZAMPIER ${ }^{1}$ e R. C. P. FARIAS ${ }^{2}$ \\ Universidade do Estado de Minas Gerais ${ }^{1}$, Universidade Federal de Viçosa ${ }^{2}$ \\ rlzampier@hotmail.com ${ }^{1}$
}

Artigo submetido em 16/01/2019 e aceito em 09/08/2019

DOI: $10.15628 /$ holos. 2019.8200

\section{RESUMO}

O presente artigo traz uma reflexão sobre a geossociabilidade e os processos de resistência e agência da mulher na sociedade contemporânea, a partir de uma análise ancorada na comédia romântica norte-americana da década de 1990, Uma linda mulher, como referência empírica do pensamento coletivo, como propõe Geertz (1976) e Híkiji (1998). Considerando as interseções Gênero, Classe e Identidade, os resultados revelam que elementos do dispositivo sociocultural, como o sistema de moda, os processos de estigmatização identitária, objetificação feminina e o imaginário romântico, a princípio, parecem contribuir para a construção de um lugar social desprivilegiado para as mulheres, tanto na obra de ficção, quanto nas práticas cotidianas. Entretanto, como evidenciado na obra, a oposição da personagem feminina às diversas formas de abusos do poder fez emergir a sua potência e a sua participação como sujeito nas relações de poder, demonstrando resistência e agência aos limites impostos pela ordem social, ampliando a sua geossociabilidade, ressignificando práticas socioculturais discriminatórias e a sua vida.

PALAVRAS-CHAVE: Gênero, Classe, Identidade Social, Geossociabilidade.

\section{BETWEEN SUBORDINATION AND AGENCY: AN ANALYSIS OF FEMININE GEOSOCIABILITY FROM THE MOVIE PRETTY WOMAN}

\begin{abstract}
This article presents a reflection on the geossociability and the processes of resistance and agency of women in contemporary society, based on an analysis anchored in the American romantic comedy of the 1990s, Pretty Woman, as an empirical reference of collective thought, as proposed by Geertz (1976) and Hikiji (1998). Considering the intersections Gender, Class and Identity, the results reveal that elements of the sociocultural device, such as the fashion system, processes of identity stigmatization, female objectification and romantic
\end{abstract}

imagery, at first appear to contribute to the construction of a socially underprivileged place for women, both in the work of fiction and in daily practices. However, as evidenced in the work, the opposition of the female character to the various forms of abuses of power has emerged its power and its participation as a subject in the relations of power, demonstrating resistance and agency to the limits imposed by the social order, increasing its geossociability, re-signifying discriminatory socio-cultural practices and their life.

KEYWORDS: Gender, Class, Social Identity, Geossociability. 


\section{INTRODUÇÃO}

A cultura é "programada" para ser vivida de modo "natural", sem grandes questionamentos. Dessa forma, grande parte dos sentidos da vida social passa despercebida tanto ao senso comum como a alguns campos da ciência. Como parte da cultura, o vestuário e as relações que as pessoas estabelecem com a moda (Bergamo, 1998), a forma como os corpos são vistos, usados e adestrados (Bourdieu, 2002; Mauss, 2003; Paim \& Strey, 2004), assim como os estigmas que interpelam a construção de identidades (Goffman, 1988), geralmente passam despercebidas no cotidiano das pessoas.

Diante dessa construção naturalizadora, as ciências sociais têm demonstrado como os dispositivos de ordem social constroem uma miopia social que faz com que as pessoas, inconscientemente, reproduzam uma ordem social que thes condicionam a um jogo de categorização de pessoas que resulta em valorização e inclusão de uns e inferiorização e exclusão de outros.

Para refletir como o dispositivo ${ }^{1}$ sociocultural e seus elementos são articulados no cotidiano individual e coletivo, especialmente das mulheres, propusemos analisar, a partir da comédia romântica Uma linda mulher (Garry Marshall, EUA, 1990), como a cultura interpela as construções das identidades e dos corpos das mulheres, restringindo seus espaços de sociabilidade e significação, assim como as condições de resistência e agência das mulheres às imposições do poder normativo.

Para tratar desse sistema de interdições, sugestões e possibilidades de trânsitos sociais delimitado a partir de marcadores socioculturais da diferença, esboçamos a noção de geossociabilidade. Esta se difere do conceito de sociabilidade concebida por Simmel (2006) como a forma lúdica da sociação², sem pretensões adicionais à própria interação social despretenciosa. 0 termo geossociabilidade, por sua vez, pressupõe as relações de poder e competição como lógica subjacente às interações sociais situadas em espaços de apropriação discriminatória as quais buscamos enfatizar na análise proposta.

A obra de ficção foi escolhida por apresentar uma dramatização da realidade, centrada no ideal romântico que é atravessado pelas desigualdades de gênero e classe. Nesse sentido, possibilita analisar traços do imaginário contemporâneo compartilhados por narrativas do cinema (Anaz, 2017) sobre a estrutura de dominação-submissão, à luz de referenciais teóricos sobre gênero, consumo, corporalidade, cultura e identidade.

\footnotetext{
1 Através deste termo tento demarcar, em primeiro lugar, um conjunto decidamente heterogêneo que engloba discursos, instituições, organizações arquitetônicas, decisões regulamentares, leis, medidas administrativas, enunciados científicos, proposições filosóficas morais, filantrópicas. Em suma, o dito e o não dito são os elementos do dispositivo. O dispositivo é a rede que se pode estabelecer entre esses elementos (Foucault, 1982, p. 244).

${ }^{2}$ A sociação em Simmel (2006) constitui-se dos movimentos das relações sociais, considerando os laços de associação que são formados, desmanchados ou reconstruídos.
} 
O interesse de análise centra-se, particularmente nas desigualdades de gênero, classe e identidade social, bem como as condições de resistência evidenciadas na relação entre os protagonistas Vivian, uma garota de programa interpretada por Julia Roberts, e Edward Lewis, um empresário bem-sucedido interpretado por Richard Gere. Suas vidas e universos começam a se entrelaçar quando Vivian, que o ajuda a chegar em seu hotel, aceita o contrato que Edward propõe para que ela seja sua funcionária, para o acompanhar nos eventos sociais e de negócios durante a semana em que estaria na cidade. Esse contrato de trabalho culmina em um romance e mudanças significativas na vida dos personagens, que iniciam com a transformação na forma de vestir e na hexis corporal de Vivian.

A hexis corporal constitui uma instância do habitus, que compreende um conjunto de percepções e acionamentos, e ao ser interiorizada em um habitus, que presume um conjunto de disposições e posturas corporais (Bourdieu, 2007). Apreender a trama partindo desse conceito permite analisar desde as questões mais visíveis imputadas nas relações com o vestuário e o corpo até os significados culturais mais ocultos que incidem sobre os trânsitos sociais, espaciais e simbólicos da mulher. Portanto, partimos do pressuposto que esse entrelaçamento de estilos de vida, classes, espaços e comportamentos, trazem à tona os jogos socioculturais que permeiam a vida desses dois personagens, pertencentes a universos sociais e simbólicos distintos.

Diante desse contexto, o conceito de gênero, compreendido como a construção sociocultural do feminino e do masculino, é pertinente para analisar as relações desiguais entre mulheres e homens, presentes na obra e nas práticas cotidianas. Dentre um conjunto heterogêneo de elementos que estabelecem a manutenção das desigualdades de gênero naturalizadas nas relações sociais e que determinam o lugar social desprivilegiado atribuído às mulheres, o imaginário romântico, como um dos elementos do dispositivo (Butler, 2010; Fanini, Santos \& Gnoato, 2017; Foucault, 1982; Santos \& Izumino, 2005), presente nos filmes do gênero comédia romântica, possui papel importante como dispositivo de opressão cultural sobre a personagem Vivian. Mas ainda assim, diante dessa e de demais contingências demonstra resistência e agência.

\section{METODOLOGIA}

Nesse empreendimento de caráter qualitativo, o método de análise fundamentou-se no paradigma hermenêutico da antropologia interpretativa de Geertz (1989). Para o referido autor, a cultura pode ser entendida como um texto que conjuga uma teia de significados entrelaçados que os atores sociais leem para interpretar e dar sentido aos acontecimentos sociais. Desse modo, a tarefa do pesquisador ao estudar a cultura é interpretá-la como um texto, tendo em vista compreender as estruturas significativas culturalmente constituídas.

Para o referido autor, o estudo antropológico é sempre a construção de interpretações em segunda mão, ou seja, interpretação de interpretações de sujeitos que constroem e reconstroem significados culturais e os incorporam em seu cotidiano. Nesse sentido, ao analisar a obra ficcional Uma linda mulher à luz da antropologia interpretativa de Geertz (1989), estamos buscando os significados construídos culturalmente que culminaram na geossociabilidade da mulher representada na obra em análise. 
Embasados em Geertz (1976), consideramos que as obras de arte não são meramente reflexos da realidade, mas uma forma de pensamento sobre a vida, que é passível de interpretação. Alinhada a essa perspectiva, Híkiji (1998) considera que a arte cinematográfica conta histórias, tempos e lugares, assim como sentimentos e perspectivas, sintetizando visões de mundo, configurando-se como formas de recorte, apreensão e organização do mundo. Assim, as obras ficcionais se relacionam de forma dialética com a realidade, ao oferecerem parâmetros ao espectador, interagindo com as categorias pelas quais a humanidade pensa e elabora a vida. Nesse sentido, concordando com Geertz (1976) e Híkiji (1998), consideramos que estudar a arte, e neste caso, um filme ficcional, constitui uma forma de investigar a sensibilidade coletiva. Portanto, a análise proposta neste artigo busca desvelar traços do imaginário contemporâneo e dos processos de significação cultural, que incidem sobre os trânsitos sociais, espaciais e simbólicos da mulher.

Para a análise e interpretação a partir da perspectiva de Geertz (1976), situada no plano semiótico, foram adotadas as quatro categorias de análise a seguir: Figurino; Cenários; Espacialidades; e Deslocamentos da personagem feminina.

\section{A TRAMA NO CAMPO DA MODA, INDÍCIOS CORPORAIS E INDISSOCIAÇÃO SOCIAL}

As características de frivolidade e futilidade individual que as Ciências Sociais tradicionais têm atribuído à moda, como se a mesma fosse restrita a indícios insignificantes (Bergamo, 2007), a mantiveram por longo tempo distante dos interesses acadêmicos. Um exemplo da hierarquia dos objetos de pesquisa é a experiência de Gilda de Mello e Souza, quando propôs investigar a moda em sua tese de doutorado, que foi defendida na USP em 1950, e colocada à margem dos estudos realizados até então. Em função de tamanho preconceito com o objeto de estudo escolhido, sua pesquisa só foi publicada como livro em 1987. Antes disso, Simmel (2008, p. 50), já considerava a moda como "uma criação complexa onde, mais ou menos, todas as tendências antagônicas da alma estão representadas".

As percepções pejorativas sobre a moda a colocam em um universo distante, que é permitido a poucos privilegiados, especialistas e consumidores legítimos. Essa visão é considerada por Bergamo (1998) como desprivilegiada e superficial, pois coloca a moda como um fim em si mesmo, em que as ações das pessoas em torno da moda se resumem em uma infinita e desmedida destruição de roupas. Muito além disso, o autor argumenta que as roupas, ao exercer sua função de intermediação simbólica, na medida em que "expressa, reproduz e nutre a série de relações existentes" (p. 2), colocam em ação as demandas sociais e culturais que estão em jogo no campo da moda.

Os pontos de venda apresentam as primeiras evidências desses jogos sociais, em que, segundo Bergamo (1998), os espaços dos comércios são moldados para constituir uma atmosfera apropriada a cada segmento de consumidores. Transcendendo essa noção para os espaços sociais de modo geral, encontramos características semelhantes em ambientes que se aderem a classes distintas. No filme em tela, evidencia-se dois espaços peculiares: Beverly Hills e Hoollywood Boulevard. O primeiro deles, destinado às elites, se caracteriza pela limpeza evidente, lojas glamourosas, atmosfera nobre em que o estilo das pessoas que passam nas ruas, assim como o 
trânsito e a organização dos ambientes são mais distantes da realidade de Hoolywood Boulevard, local destinado a classes inferiores, tumultuado, obscuro e marcado pela violência, drogas, atividades ilícitas, enfim, um conjunto de características estigmatizantes que configuram o lócus das classes desprivilegiadas, de pessoas invisíveis socialmente. Analogamente à visão de Bergamo (1998), há muito mais entre esses dois bairros do que o fato de existir espaços e consumos elitizados e outros não. Sob a perspectiva do referido autor, a análise desse tipo de processo exige o exame dos interesses, ou demandas que orientam o uso simbólico dos bens no contexto das relações entre os vários grupos sociais, considerando suas respectivas posições na estrutura social.

O processo de indissociação social se constitui de dois movimentos, que Bergamo (1998) denomina demandas, cuja natureza varia conforme a posição do indivíduo na estrutura social. A demanda de legitimação e a demanda de compensação demonstram a distância entre dois universos que a sociedade contemporânea insiste em manter. De um lado estão as elites, que buscam legitimar as credenciais de sua classe por meio de demandas de legitimação, ou seja, esforços para garantir instrumentos que possam legitimar uma posição privilegiada na sociedade, mediante o consumo de símbolos que as permitem criar uma indissociação entre si mesmas e um universo glamouroso ao qual pertencem. Para esse grupo, comprar roupas se trata de renovar indícios e meios de expressão do indivíduo e seu mundo, supostamente mais qualificados. Por outro lado, as classes menos abastadas estabelecem outra relação com o vestuário. Excluídos dos mecanismos considerados legítimos do mundo da moda, como a mídia, desfiles e revistas, a indissociação social para eles é uma questão contingencial. Em seu universo os indícios de exclusão estão por todo lado. Assim, a demanda de compensação consiste em um esforço para "destruir", ou seja, deslegitimar os traços que "colam" o indivíduo em sua contingente posição social inferior. Nesse sentido, os corpos ganham evidência para dar força ao empreendimento de construção da distinção pessoal.

Desde a primeira cena, Vivian está marcada por sua posição de classe, por meio de indícios tais como, o apartamento minúsculo que é dividido com a amiga, os móveis simples, a desorganização e excesso de coisas no mesmo espaço. Além disso, como sua amiga gastou o dinheiro com drogas e festa, ela é obrigada a sair pela escada de emergência para fugir do cobrador. Todos os indícios de sua indissociação a uma camada social desprivilegiada são reforçados pelas roupas que, além de "colá-la" em seu universo de pobreza (as botas velhas, desgastadas e com clipe prendendo o zíper), estão muito associadas à sua profissão, fazendo uma analogia ao uniforme de trabalho, como afirma Farias (2010), que comunica símbolos relativos à imagem empresarial, no caso de Vivian, a imagem da profissão de garota de programa/prostituta, indicando o pertencimento a esta, em que esse "uniforme" constitui parte de um pacto silencioso de comprometimento e adesão às normas sociais.

Já Edward, um empresário bem-sucedido de Nova York, frio e voraz na condução de seus negócios, vive em meio a pessoas importantes, frequentemente relacionadas aos negócios, como empresários e políticos. Sua aparência elegante, vestuário requintado, assim como suas rotinas suntuosas e sua hexis corporal, expressam seu pertencimento a uma escala mais rarefeita da estrutura social. 
A distância do universo social de ambos é evidenciada quando Vivian entra no hall do hotel em que Edward estava hospedado e as pessoas, de estilo mais sofisticado, lançam olhares contestadores para ela. Vivian, por sua vez, recorre ao seu corpo como recurso para reagir àquela situação desconfortável. Apesar de Edward ter the dado o seu casaco para que ela ficasse mais apropriada àquele espaço, à espera do elevador, diante de um casal mais maduro, cuja mulher a observava com desdém e olhar de desaprovação desde sua entrada no hall do hotel, Vivian age rompendo a lógica hegemônica a qual é submetida. A personagem feminina encontra a possibilidade de agência dando mais relevo à situação mencionando a Edward que sua meia calça havia puxado um fio, deixando sua perna à mostra e, logo em seguida, ironiza, dizendo que na verdade ela não estava de meia calça, e entra no elevador onde assenta com uma perna aberta e em cima do sofá, em uma atitude de provocação contra a mulher, que se irrita, puxa seu marido, impedindo-o de entrar no elevador e o manda fechar a boca.

O manejo do corpo de forma sedutora faz parte do que Mauss (2003) chama de técnicas do corpo, evidenciando que o trato com o corpo e as posturas corporais não são naturais, mas são modeladas conforme a cultura e o grupo de pertencimento. A postura e os gestos também evidenciam a indissociação entre o indivíduo e sua posição na estrutura social, o que acontece com a personagem Vivian, cujo corpo não foi "adestrado" para se inserir naquele espaço, da mesma forma que os corpos da elite de Beverly Hills não foram socializados para a expressão corporal que Vivian manejava com naturalidade e a fornecia capacidade de ação diante dos abusos do poder normalizador.

Diante da ausência de domínio dos códigos culturais do universo do outro, o caminhar nas ruas à procura de um vestido para acompanhar Edward em um jantar de negócios, Vivian vivencia um processo de exclusão. Suas roupas, posturas, gestos e maneira de andar chocam as pessoas que caminham por Rodeo Drive, como se aquele corpo e roupas não fizessem parte daquele lugar. 0 processo de indissociação social faz dela uma excluída naquele espaço. Como a sua presença não é bem-vinda, ela não consegue comprar o vestido sozinha, por ser considerada desqualificada pelas vendedoras das boutiques que entrou, mesmo possuindo dinheiro para comprar. Assim é expulsa da loja, onde seus indícios de indissociação social impedem sua socialização naquele espaço, no qual ela não é reconhecida.

Após saber que Vivian era acompanhante de Edward, considerado um hóspede importante, o Sr. Thompson, gerente do hotel, pede a sua amiga Bridget, vendedora de uma loja de roupas femininas, para ajudar Vivian a comprar o vestido para o jantar com Edward. Após a compra do vestido e sapatos, inicia-se um processo de adestramento do corpo, com a ajuda do Sr. Thompson, que instrui Vivian em relação ao uso dos talheres à mesa, pois a experiência no restaurante seria um desafio para o seu corpo, exigindo dele novos modos e uma hexis corporal que ela ainda não tinha adquirido.

A inabilidade para manusear os talheres torna essa cena uma das mais hilárias do filme, pela falta de adestramento do corpo para manusear aquele conjunto de artefatos, o que indica que o papel do riso no cinema vai além do entretenimento. Como argumenta Weakland (1995), as obras ficcionais não só refletem premissas culturais, mas também têm potencial para influenciar o comportamento das pessoas que os assistem. Assim, ao encantar, seduzir e fazer rir, as cenas 
ensinam noções socialmente concebidas, como aquelas relativas a classe, que é enfatizada na presente seção. Nesse sentido, a cena supracitada não apenas promove o entretenimento aos espectadores da obra, mas também Ihes transmitem significados culturais relativos às fronteiras de classe e os mecanismos de discriminação sociocultural que, nesse caso, se materializa nas técnicas corporais que suscitam o riso que, por sua vez, permite naturalizar essas noções. Por isso, reiteramos que a análise de obras ficcionais permite explorar os significados e os padrões de pensamento coletivo, como preconiza Geertz (1976). Tornando-se, portanto, oportuna para a análise dos princípios e valores socioculturais ao longo do tempo, suas influências sobre as pessoas e a resistência das mesmas.

O encontro da protagonista com esse contexto sociocultural tão diverso ao que estava habituada e sob uma nova dinâmica de poder produz efeito sobre ela e a impulsiona à mudança. Mas isso não implica na simples sujeição à essa realidade cultural, pois as mudanças promovidas em si mesma e em seu entorno são em parte produzidas por sua capacidade de ação política e de resistência, como advoga Butler (2010). No filme, a mudança social da personagem, de um lugar social desprivilegiado, estreitamente relacionado às assimetrias de gênero, especialmente por ser uma prostituta, perpassa prioritariamente pelas mudanças no vestuário e incorporação das técnicas corporais de uma alta classe. O filme evidencia as mudanças de Vivian em relação às roupas e ao corpo, a partir do momento em que Edward a procura no bar do hotel e a encontra deslumbrante em outras vestes, já assumindo uma postura que evidencia traquejo social e elegância.

Edward, por viver em uma esfera mais "rarefeita" do consumo, expressa em várias situações o processo de indissociação social entre o seu comportamento e sua classe, por meio do capital cultural, das ações de consumo, das técnicas do corpo e da linguagem rebuscada. A cena em que fica mais explícito o uso de sua posição social e seu poder aquisitivo é quando ele vai a uma boutique para ajudar Vivian a comprar roupas. Na loja, Edward reivindica muita bajulação para Vivian, afirmando que eles iriam gastar uma quantia obscena. Ao fazer isso, ocorre uma transferência de poder, em que Vivian ganha o foco de atenção naquele espaço que, mesmo que temporariamente, a "descola" da contingencial situação desprivilegiada e a eleva a uma situação de poder.

A partir de então, as roupas, acrescidas das normas de etiqueta ensinadas pelo Sr. Thompson, especialmente, com o uso dos talheres e desenvoltura para o primeiro jantar de negócios em que Vivian participou com Edward, inscrevem no corpo dessa personagem feminina, traços culturais de uma classe distinta da sua de origem. Suas novas vestes parecem moldar o corpo e controlar os gestos que são próprios de uma classe subalterna. Com a mudança nas roupas e na hexis corporal, os olhares dos transeuntes das ruas, dirigidos à Vivian, se modificam. Assim, o espanto e a repugnância dão lugar ao deslumbramento, ao reconhecimento de que ela se assemelha à elegância e à sutileza das mulheres da elite. Portanto, o adestramento do corpo (Mauss, 2003) de Vivian, a que ela mesma se inclinou e criou meios para realizar, ocorre por meio de vários mecanismos, em que o aprimoramento das técnicas corporais é complementado pela moldagem que as roupas e a aquisição de capital cultural exercem no corpo.

Apesar da aparente imagem dos sonhos que a mudança de Vivian remete, as coerções estéticas a que ela se submete, a partir de então, são mais fortes ainda que a de sua vida anterior. Sob o novo visual de Vivian, a exigência quanto ao controle do corpo e a estética reflete a 
elucubração de Goldenberg (2006) acerca da ansiedade que as coerções estéticas têm introduzido nas pessoas, exigindo das mesmas alto nível de controle sobre o corpo e a aparência.

Exemplo disso ocorre em cena na qual ao sair do hotel com Vivian, que usava um vestido vermelho e um colar de brilhantes para assistir a uma ópera (evento próprio das elites, com capital cultural para apreciá-lo), Edward comenta que ela fica mais linda e mais alta quando não está rebolando. Além do elogio a fala de Edward também possui caráter normativo, pois sugere limites de movimentação do corpo em nome de uma suposta elegância, uma das formas de coerção imposta pela sociedade para fins de discriminação social.

No último dia do contrato, durante o café da manhã, o corpo de Vivian demonstra já ter sido adestrado aos imperativos da classe de Edward. Ao sentar-se à mesa e não sobre a mesa como era seu costume, ela cruza as pernas elegantemente e as encobre com o roupão. No entanto, Vivian também adestra o corpo de Edward para outras experiências, como o lazer informal, aparentemente inexistente em sua vida de executivo, exclusivamente atrelada às estratégias de negócios. Vivian retira os indícios de formalidade existentes nas roupas de Edward, para que ele possa desfrutar de momentos de descontração e relaxamento, como retirando seus sapatos, meias, casaco e gravata para que ele possa caminhar descalço sobre a grama dos jardins. Entretanto, a resistência e o incômodo o fazem voltar à postura original, recolocando o traje, como se sua hexis corporal o chamasse à ordem.

No caso de Vivian, mesmo que seu corpo estivesse encoberto com outras vestes, não foi suficiente para conduzir, até aquele momento, o "descolamento" de sua condição inicial, devido ao estigma da prostituta. Na seção a seguir será discutido como o estigma não evidenciado no corpo a interpela forçando-a a se manter numa condição social desprivilegiada. Para tanto, a análise foi conduzida, principalmente a partir da concepção de estigma de Goffman (1988).

\section{O ESTIGMA COMO BARREIRA AO “DESCOLAMENTO” IDENTITÁRIO}

Originado na Grécia, o termo estigma designava marcas e sinais, inscritos nos corpos, normalmente feitos com fogo ou cortes que eram utilizados para informar o status moral da pessoa, evidenciando algo pejorativo sobre a mesma, como por exemplo, que era um escravo, criminoso ou traidor. Embora esteja originalmente atrelado às marcas físicas e visíveis, na atualidade faz mais sentido associá-lo à desgraça ou condição de classe (Goffman, 1988).

Simbolicamente, o estigma é inerente às relações sociais e ao processo de categorização de pessoas, uma vez que as pessoas se classificam ao interagirem no mundo social. Diante de um estranho as pessoas levantam um conjunto de atributos e preconcepções que se transformam em expectativas normativas rígidas, que se consolidam em exigências sobre a identidade social ${ }^{3}$ desse estranho. Essas exigências configuram a identidade social virtual, que pode ser diferente dos atributos e categorias definidoras da identidade social real desse sujeito (Goffman, 1988). Logo, o estigma é caracterizado quando o efeito da incongruência entre identidade social virtual e identidade social real é um grande descrédito para a pessoa. Desse modo, para esse autor, o estigma

\footnotetext{
${ }^{3}$ Goffman (1988) utiliza o termo identidade social, por considerá-lo mais apropriado que "status social".
} 
interpela as relações sociais e o processo de classificação das pessoas e resulta em atribuição de espaços a cada categoria de pessoas na sociedade.

No filme Uma linda mulher, o Hollywood Boulevard, lugar da prostituição e das classes subalternas, onde Vivian reside, o estigma da profissão e da identidade social dão evidências que indissociam a pessoa à sua condição social. Nesse espaço determinado para o seu corpo e a sua profissão, o estigma não é um problema nas relações com as pessoas, diferentemente de sua incursão por Beverly Hills, onde o estigma salta aos olhos das pessoas estranhas, que demonstram rejeição ao que veem. O que resulta em uma restrição de espaços de socialização em função do estigma, pois segundo Goffman (1988), apesar de o estigma ser capaz tanto de excluir como incluir o estigmatizado, de um modo geral o condiciona a um contexto de exclusão, descrédito e repugnância.

A amenização desses efeitos é relativa, pois apesar de o estigma geralmente ganhar mais relevo aos olhos de pessoas estranhas, menos familiarizados com o indivíduo ou situação, a intimidade pode não reduzir necessariamente o menosprezo, uma vez que pessoas típicas, ou ditas "normais" podem manter o preconceito das vizinhas, habitantes de colônias estigmatizadas, exemplifica Goffman (1988). Por outro lado, pessoas que passam menos tempo com o estigmatizado podem lhe aceitar mais facilmente do que aquelas que convivem cotidianamente. Logo, o autor supõe que o significado de um estigma é mais profundo para as pessoas mais íntimas do que para os estranhos. Ainda assim, a proximidade constitui uma alternativa substantiva para a ressignificação do estigma a partir da identidade pessoal do indivíduo.

A unicidade da identidade pessoal de Vivian entra em jogo, criando a diferenciação dessa personagem feminina, somente quando o estigma da garota de programa fica menos em evidência. Porém, nem sempre a proximidade é passível de ser construída no âmbito das relações sociais em diferentes espaços. Por isso, a personagem sentiu a rejeição e exclusão nas lojas, nos eventos e no hotel. Na relação com o gerente do hotel, que reconheceu sua condição desde o primeiro contato, o processo de aceitação só inicia na medida em que a posição do empresário rico a quem ela acompanha sobrepõe o estigma de garota de programa. Entretanto, é o carisma de Vivian que parece contornar definitivamente essa barreira com o Sr. Thompson, que acaba sendo fundamental para a mudança social de Vivian. Já Edward, desde o início, apresentou maior sensibilidade para enxergar as características particulares dessa mulher, que o fez se apaixonar por ela.

Porém, o estigma que a cerca não é totalmente apagado. No último dia do contrato, após tomarem o café da manhã, Edward revela que terá que ir para casa, mas pretende ir vê-la novamente. Em sua proposta, Edward a tiraria das ruas e da prostituição e a manteria em condições financeiras e em um apartamento, sob a condição de que ela estivesse à disposição para quando ele passasse pela cidade, sem assumir um compromisso mais sério. Para Vivian, isto seria o mesmo que continuar sendo uma prostituta, mas com um dono. Ao evidenciar em expressão facial tal frustração de Vivian, Edward diz que nunca a tratou como uma prostituta, embora ele tenha acabado de tratá-la como tal.

A cena demonstra que, apesar da mudança de performance de Vivian, com o aprimoramento das técnicas corporais, conduta e vestuário, o estigma permanece dissimulado na história de amor. 
As tentativas de ocultamento do estigma e a acentuação da identidade pessoal para reduzir o distanciamento entre identidade social virtual e a identidade social real parece colidir com o próprio estigma.

A identidade pessoal, desempenha um papel estruturado e padronizado na organização social, distinguindo os indivíduos uns dos outros por sua unicidade. Nos estigmatizados, tanto o estigma quanto o esforço de ocultamento e correção se fixam na identidade pessoal (Goffman, 1988). No caso das prostitutas, existe a possibilidade de preservação da identidade pessoal por meio da mudança de nome, mesmo não oficialmente, podendo conduzir à ruptura entre o indivíduo e aquilo que pretende obscurecer. Vivian como prostituta se permitia ser chamada pelo nome que 0 cliente gostasse. Entretanto, durante todo o filme, quando todas as pessoas lhe perguntaram seu nome, ela prontamente afirmava que era Vivian. A mudança do nome no contexto do filme, não possui como objetivo a autopreservação ou manipulação da situação, mas, parece estar mais relacionada com a possibilidade de atender ao fetiche particular de cada cliente.

O risco de descoberta e a possibilidade de repercussões negativas insere ao processo de ocultamento um conjunto de tensões e instabilidades (Goffman, 1988). Assim, a descoberta concretiza uma reação negativa em cadeia, com prejuízo nas relações constituídas, na situação social atual, na imagem corrente atribuída pelas pessoas e na imagem e reputação que serão projetadas no futuro. Esse problema levantado por Goffman (1988) está relacionado com a necessidade de preservação da imagem em relação aos parentes, amigos ou conhecidos. Entretanto, surge algo similar que coloca em risco tudo o que Vivian estava vivendo: Edward, no jogo de polo, conta a seu amigo Stuckey, advogado e braço direito em sua empresa, que Vivian é uma prostituta. De posse da informação, Stuckey chega até Vivian e a pergunta sobre a possibilidade de realizar um programa com ela após Edward a deixar, como se pudesse acessá-la como qualquer objeto.

Como Vivian parecia já estar muito à vontade com sua nova identidade e condição, em meio às pessoas ricas, ela fica muito incomodada com a investida de Stuckey. Além disso, aquela realidade, que veio novamente à tona, não fazia mais parte de seu desejo, de sua vida, sendo algo que Vivian parecia querer se distanciar ou esquecer. Dessa forma, a possibilidade de a informação ser difundida entre as pessoas do grupo de Edward, a colocava em risco de constrangimento naquele ambiente. Portanto, a "dor" do estigma parece ter sido mais forte nesse momento, no qual ficou nítida a dificuldade de Vivian para lidar com aquela situação diante de seu novo contexto sociocultural, que the exigia maior resiliência e capacidade de ação para se tornar sujeito e se opor aos abusos do poder normalizador, que tenta circunscrever os limites dos desejos e possibilidades.

Diante disso, a próxima seção é dedicada a reflexões acerca da capacidade de ação emergente nas relações de poder e subordinação que permitem a personagem Vivian, nas tramas da obra de ficção, e as mulheres, na vida real, se tornarem sujeitos, nas quais a subordinação, apenas aparentemente é a única possibilidade. 


\section{GÊNERO, CORPO E AGÊNCIA}

A fim de analisar as nuances que circunscrevem a atuação social das mulheres, emergentes na obra de ficção e na sociedade, a partir de um enfoque nas relações de poder e agência, torna-se oportuno considerarmos a definição da categoria gênero de Scott (1986). A conceituação da autora vai além da proposição de gênero como elemento integrante das relações sociais, cuja orientação se baseia nas diferenças percebidas entre os sexos. A autora acrescenta à sua teorização a ideia de que a categoria gênero é uma forma ou campo primário no qual ou por meio do qual as relações de poder são significadas, ou o poder é articulado.

Como salientam Santos e Izumino (2005), apreender as relações de gênero a partir da perspectiva de Scott permite uma análise mais apropriada das complexas e dinâmicas relações de poder subjacentes às relações de gênero. Portanto, no presente trabalho, assumimos, assim como advogam as autoras supracitadas, as relações de gênero como dinâmicas de poder, ao invés de apreendê-las como resultado de uma relação antagônica e estática, que culmina numa noção simplista de dominação masculina. A partir dessa perspectiva, compreendemos que nas dinâmicas de poder entre homens e mulheres, nas quais o masculino é privilegiado pela ordem social, as mulheres não são indivíduos meramente passivos, mas constituem-se como sujeitos, dotadas de capacidade de ação política, ou seja, possuem agência.

Portanto, assim como Butler, assumimos que o indivíduo se torna sujeito ao experimentar a subordinação nas relações de poder, dando origem a sua forma de poder, a potência, ou seja, sua capacidade de ação que amplia as suas possibilidades de ressignificar a própria vida:

O poder que dá origem ao sujeito não mantém uma relação de continuidade com o poder que constitui a sua potência (capacidade de ação). Quando o poder modifica o seu estatuto, passando a ser condição de potência, converte-se em a própria potência do sujeito (constituindo uma aparência de poder na qual o sujeito aparece como condição de seu próprio poder), se produz uma inversão significativa e potencialmente permitida (Butler, 2010, p. 23).

A partir desses pressupostos e considerando as construções sociais nas quais o corpo feminino ganha relevo nas relações de gênero e nas dinâmicas de poder apresentadas no filme e na sociedade, assumimos o corpo como categoria analítica privilegiada nesta seção. Com isso, não ignoramos a complexidade do fenômeno estudado, mas buscamos compreender as dinâmicas de poder mediada pelo marcador social da desigualdade evidente na obra que ancora a análise proposta.

Conforme Paim e Strey (2004), o corpo feminino se tornou objeto de consumo, pois o culto ao corpo e a valorização da aparência marcam fortemente a sociedade contemporânea. No filme, a beleza e a preocupação com a aparência estão claramente em evidência. Em todos os cenários, pode-se notar a ênfase na beleza feminina, ancorada nos corpos magros, altos e em trajes elegantes. Mulheres de variadas idades figuram deslumbrantes, impecáveis quanto à aparência, assim como sugere o próprio título do filme e a canção principal da trilha sonora. Essa constatação vai ao encontro da afirmação das autoras, de que a valorização da juventude, beleza e aparência, com a 
manutenção de um corpo esbelto, faz parte de uma regulação social, na qual as mulheres são mais pressionadas para cumpri-la, mantendo-as afastadas de problemas importantes da sociedade.

A construção do corpo perpassa tanto pela biologia quanto pela cultura, sendo o corpo a interface entre a individualidade e o social. Isso porque o corpo de mulheres e homens é uma construção cultural, produto das diferenças de gênero construídas socialmente ao longo da história. As mulheres são socializadas desde a infância sobre o discurso normativo de corpo frágil, passivo e sem força física, sendo a beleza cultuada como a essência do que é ser mulher. Já aos corpos masculinos são atribuídas as características força, agressividade e virilidade. Nesse sentido, não somente os corpos, mas os gêneros feminino e masculino são concebidos e naturalizados nas relações sociais sob condições de desigualdade e de assimetria de poder, cujo efeito é o privilégio dos homens e a atribuição de um lugar social menos prestigiado às mulheres (Paim \& Strey, 2004).

Como indica Bourdieu (2002), os padrões inconscientes de estruturas concebidas historicamente pela sociedade foram construídos sob uma perspectiva androcêntrica, em que a divisão entre os sexos determina a ordem das coisas. Assim, a desigualdade entre os gêneros é fruto dessa construção sexual, em que o imaginário do masculino é predominantemente construído como ativo e o feminino passivo. Com efeito, tais disposições engendram limites à espacialidade da mulher, comparada à esfera de atuação masculina e suas orientações com relação às pessoas e coisas na sociedade.

Como a aparência é o fator central na definição do indivíduo, historicamente, a imagem da mulher é associada à beleza, sendo que as regulações sociais recaem mais fortemente sobre os corpos femininos, já que o ideal de beleza incide sobre ela como um dispositivo repressivo. $\mathrm{Na}$ atualidade, a beleza além de ser um dever social, se tornou uma obrigação moral, portanto, o fracasso no alcance da beleza é julgado como uma incapacidade individual (Novaes, 2011). Além disso, Paim e Strey (2004) argumentam que apesar das conquistas femininas do último século, as exigências impostas ao corpo da mulher, de estar sempre bela e jovem, esconde em sua suposta independência, os mecanismos para a sua submissão e inferiorização. O filme reproduz bem isso, pois as mulheres são apresentadas como objeto de consumo, com atribuições associadas ao feminino, como prostitutas, secretárias, consumidoras etc. Principalmente em Beverly Hills, a atividade das mulheres parece girar em torno do universo da beleza e do cuidado, em que aparecem fazendo compras ou cuidando de eventos, como a esposa de Stuckey, cujos papeis são principalmente relacionados à organização dos eventos sociais de negócios, como uma extensão das tarefas da casa e acompanhamento do marido nesses eventos.

As relações desiguais entre os gêneros condicionam as mulheres a assumirem profissões e papeis menos importantes na sociedade. Apesar dos avanços da humanidade o processo de emancipação feminina ainda é constrangido pela perspectiva androcêntrica reproduzida amplamente (Bourdieu, 2002).

Os papeis sociais de homem e de mulher reproduzidos no filme corroboram com essas afirmações, pois os homens são responsáveis pelos negócios, representados como sujeitos bemsucedidos, enquanto as mulheres são retratadas como suporte para o trabalho dos homens, que os servem, como objetos de consumo. Nesse sentido, a identidade social virtual (Goffman, 1988) da 
personagem Vivian era desqualificada naquele meio em vários aspectos: por ser mulher, por carregar os estigmas da profissão de prostituta, cujas violências a que estão submetidas, estão atreladas à violência de gênero, que ocorrem cotidianamente inclusive nos espaços públicos (López Molina, 2018; Silva \& Ximenes, 2017), e da classe, cujas interseções a colocava, na visão de Stuckey, como um ser infinitamente inferior. Isso o faz pensar que Vivian, por ser uma mulher, garota de programa e pobre, estivesse à disposição dele e não tivesse o poder de escolha de seus parceiros. Quando Stuckey encontra Vivian sozinha no hotel, ele a assedia sexualmente, além de agredi-la fisicamente e moralmente, até que Edward chega e o expulsa do apartamento depois de tirá-lo de cima de Vivian e lhe dar um soco no rosto. Mais do que tornar a mulher submissa, os padrões sociais androcêntricos de que fala Bourdieu (2002), empoderam os homens ao inferiorizar e restringir as condições de sociabilidade e a independência das mulheres, a ponto de permiti-los pensar que podem e devem agir como Stuckey, para reafirmar sua masculinidade e seu poder. Como reforçam estudos recentes (Cardoso, Soares \& Lima, 2017; Fanini, Santos \& Gnoato, 2017; Rezende \& Silva, 2018; Silva \& Ximenes, 2017), essa violência, física e simbólica é naturalizada nas práticas cotidianas, que dificultam a emancipação feminina e a construção de representações sociais alicerçadas na equidade de gênero.

A perspectiva androcêntrica encontra na sociedade moderna mecanismos muito eficazes para a sua manutenção como o mito da beleza, podendo ser considerada a única trincheira que precisa ser superada para a emancipação feminina. E talvez essa seja a mais difícil barreira a ser superada, pois na medida em que as mulheres conseguiram espaço e venceram obstáculos, mais estridente foi a imposição das imagens da beleza feminina sobre elas. Prova disso, é a aceleração dos distúrbios alimentares, a crescente procura por cirurgia plástica com finalidade unicamente estética, o aumento vertiginoso do consumo e a expressão do gênero pornográfico. $O$ mito da beleza se fortaleceu para substituir a coerção social imposta pela ideologia da domesticidade da mulher casta e passiva, que perdeu o poder de controle que tinha sobre as mulheres, embora ainda não tenha desaparecido (Wolf, 1992).

Sutilmente, sob a aparência de liberdade, o ideal de beleza tenta encarcerar a mulher no universo feminino. Assim, as mulheres precisam lidar com um cenário de contradições que cercam a possibilidade de emancipação e igualdade. Como afirma Farias (2009), além de serem incentivadas a atender ao ideal de beleza, principalmente por estímulos provenientes da publicidade e do conjunto de características propagado pelas agências de modelo, por exemplo, as mulheres ainda precisam se encaixar nos papeis tradicionalmente atribuídos a ela. Dessa maneira, as mulheres vivenciam uma experiência de contradição, pois ao mesmo tempo em que devem ser dóceis, frágeis, submissas e dedicadas ao lar, ao marido e aos filhos, precisam ser belas e sensuais.

A aparente liberdade garantida pelo poder de consumo, uma vez regida pela ordem masculina, legitima a visão androcêntrica e a submissão das mulheres. Bourdieu (2002) argumenta que a naturalização dessa ética ocorre a partir dos antagonismos entre os princípios das identidades masculina e feminina que se inscrevem nas formas de servir do corpo e manter a postura do mesmo. As roupas, de acordo com o autor, situam-se nesse contexto como mecanismos de contensão dos corpos, uma forma de confinamento simbólico. Nesse sentido, as roupas femininas além do efeito de dissimular o corpo, reafirmam a ordem continuamente. 
No filme, ao ser convidada a se inserir em um novo universo, Vivian passou a usar vestes mais sofisticadas, elegantes, mas que, ao mesmo tempo, limitavam as ações livres do seu corpo, atreladas às técnicas corporais (Mauss, 2003) que o induzem a entrar em uma ordem social em que a visão androcêntrica impõe às mulheres modos de conduta, sem lhes proibir explicitamente. As novas roupas de Vivian corroboram com a assertiva de Bourdieu (2002) de que as saias, salto alto e bolsas impedem, ou ao menos desencorajam, uma série de atividades e movimentos. Dessa forma, o dispositivo da ordem social androcêntrica impõe um paradoxo às mulheres, de modo tão sutil, mas ao mesmo tempo tão eficaz, entre aquilo que as fazem sentir livres e as aprisionam.

Por outro lado, é dessa relação e condição de subordinação que emerge a capacidade de ação da personagem feminina mesmo em relações de poder desfavoráveis a ela. A partir da potência proeminente de sua ação como sujeito, como propõe Butler (2010), Vivian encontra as possibilidades de ressignificar a sua vida. Na medida em que os novos códigos culturais e técnicas corporais são dominados por ela, juntando-se às seu repertório cultural e à sua personalidade, em um processo de internalização e exteriorização do habitus, ela é capaz de criar condições para ressignificação e mudanças nas práticas sociais e subjetividades, tanto dela, como de Edward.

A resistência aos condicionamentos sociais e a agência de Vivian são evidenciados nas diversas interações que estabelece. Por mais que a interseção gênero, profissão e classe a colocasse em condições de subordinação e abusos do poder normalizador, como aconteceu nas lojas, nas interações com o advogado de Edward e na própria relação amorosa com este último, nessas mesmas relações foram engendradas as condições de resistência e possibilidade de Vivian, revelando sua potência e a constituindo como sujeito nessas relações. Dito de outra forma, a personagem feminina faz seu corpo escapar aos limites impostos pela heteronormatividade, a partir da subversão de gênero, como salientam Cardoso, Soares e Lima (2017), que provoca um deslocamento ao agir no interior da própria norma, a colocando em questionamento, constituindo uma forma de enfrentamento às violências de gênero.

A violência simbólica que sofrem as mulheres está centrada basicamente na constatação de que as mesmas são objetos de uma economia de bens simbólicos (Bourdieu, 2002). Para o autor, o dispositivo central da inferioridade e exclusão da mulher no campo das trocas simbólicas é o mercado matrimonial (base da ordem social), no qual as mulheres são objetos de consumo, cuja função dos símbolos adquiridos é favorecer a continuidade e o aumento do capital simbólico dos homens.

Sobre esse aspecto Vivian vivencia uma situação paradoxal: Como prostituta, ela não se rendia a possibilidade de ser dominada por um cafetão e resistia ao controle de um homem sobre sua vida profissional e pessoal. Por isso, a proposta inicial de Edward para a continuidade do romance, sem um compromisso, não a agrada, embora aparente ser uma oportunidade de se livrar da condição de prostituta. Porque para ela, a ideia de ficar à disposição de Edward e ser bancada por ele era como algo que a resumiria à condição de prostituta de apenas um homem.

A oferta de Edward, de um apartamento, carro e a bajulação de muitas lojas, para que ele pudesse vê-la quando estivesse na cidade, contrasta com o sonho de infância da personagem que, ao ser trancada no sótão por sua mãe como punição, idealizava ser libertada da torre como as 
princesas dos desenhos infantis, por um príncipe. Portanto, a ideia de ser colocada em um apartamento, soava como os mesmos aprisionamentos que rejeitava. Como ela mesma disse, demonstrando sua potência em meio à relação, "isso é pura geografia", ou seja, continuaria como mera prostituta, prisioneira de um só cliente.

Após vivenciar esse conflito e um suposto adeus entre o casal, o tão sonhado conto de fadas se materializa na vida de Vivian em uma das cenas de maior apelo emocional da obra. Edward a surpreende, chegando na limusine branca, como se estive em um cavalo, com o guarda-chuva erguido em uma das mãos, como se fosse uma espada, e um buquê de rosas em outra, chamandoa: "princesa Vivian, desça". Reforçando a referência ao conto de fadas, Edward enfrenta seu medo de altura e sobe pela escada de incêndio para chegar onde Vivian estava, no último andar, em uma clara analogia ao encontro do cavaleiro com a princesa no alto da torre do castelo, superando as intempéries, como nas relações impossíveis idealizadas no imaginário e nas obras literárias, com as quais sonhava a personagem.

As possibilidades de sonho, riso e magia, assim como as noções de feminilidade e de masculinidade, representações de amor e felicidade, valores, visões de mundo e padrões de comportamento engendradas em práticas discursivas como aquelas naturalizadas no cinema, são elementos de um dispositivo que reinscreve em seus códigos e convenções técnicas e estéticas um ponto de vista ainda predominantemente masculino, eurocêntrico e heterossexual. Apesar de a protagonista ser submetida à diversas coerções socioculturais nos trânsitos sociais que executa na trama, a mesma constitui-se como sujeito, superando os limites que o poder normatizador a expõe, demonstrando sua resistência e sua potência para remodelar circunstâncias, pensamentos e pessoas em espaços nos quais as relações desiguais de poder, a princípio, sugeria a passividade, a marginalização e a exclusão.

\section{CONSIDERAÇÕES FINAIS}

Buscando refletir sobre as dinâmicas de poder incutidas e emergentes nas relações entre pessoas em situação de desigualdades sociais, este artigo utilizou como referência empírica do pensamento coletivo a obra de ficção Uma linda Mulher (Garry Marshall, 1990). Para tanto, partimos da perspectiva metodológica de Geertz (1976), considerando que estudar a arte nos possibilita explorar uma sensibilidade essencialmente coletiva. Com suporte nesse pressuposto, na perspectiva de poder/agência em Butler (2010) e na lógica das interseccionalidades, objetivamos apreender traços do imaginário contemporâneo representado no cinema sobre as relações assimétricas de poder que se estabelecem a partir de convergências dimensionais de gênero, classe e identidades sociais e refletir sobre os processos de resistência e agência de sujeitos subalternizados.

A partir das relações que são estabelecidas do encontro e convívio do par romântico Vivian e Edward, constatamos que o dispositivo sociocultural ainda amplamente orientado pela perspectiva masculina, eurocêntrica e heterossexual, sugere e impõe uma estrutura de dominaçãosubmissão que circunscreve a geossociabilidade das pessoas. 
Os resultados demonstraram que esse sistema de interdições, sugestões e possibilidades de trânsitos sociais em espaços distintos, são delimitados com base em marcadores socioculturais da diferença, como as dimensões gênero, classe e identidade social, configurando a geossociabilidade do indivíduo.

É possível perceber que tanto na obra como na vida social contemporânea os trânsitos sociais, espaciais e simbólicos da mulher são estreitados em suas relações, cuja estrutura é orientada para o privilégio dos homens. Entretanto, a lente teórico-metodológica adotada neste trabalho permitiu perceber os processos de resistência e agência emergentes das relações de poder experienciadas pela personagem Vivian, cujo aparato era voltado para a marginalização e submissão da mesma. Os resultados da análise não compatibilizam com a ideia de assujeitamento e passividade das pessoas em condições de subordinação, pois evidenciamos que, são nessas mesmas condições que são forjados os sujeitos, com sua resistência e potência.

Nesse sentido, as constatações deste estudo corroboram a perspectiva de poder e agência em Butler (2010) ao vislumbrar por meio da lógica das interseccionalidades as diferentes configurações e efeitos do poder nas experiências da personagem Vivian e a subversão de uma ordem social hegemônica, possibilitando a ressignificação de práticas socioculturais e identidades sociais. Com isso, o presente estudo acumula contribuições no sentido de compreender como emergem a resistência e agência de sujeitos historicamente marginalizados como a personagem Vivian, mulher, pobre e prostituta. Contudo, a personagem, longe de constituir um ser passivo, ampliou sua geossociabilidade, provocando um turbilhão de mudanças em si mesma e ao seu redor, a partir de sua potência e subversão.

\section{REFERÊNCIAS}

Anaz, Sílvio Antonio Luiz. (2017). O sobre-humano nos imaginários cinematográficos bemsucedidos. Comun. Mídia Consumo, 14(41), 171-194, Set./Dez.

Bergamo, Alexandre. (2007). A experiência do status: roupa e moda na trama social. São Paulo: UNESP.

Bergamo, Alexandre. (1998). O campo da moda. Rev. Antropol., 41(2), 137-184. Disponível em: http://www.scielo.br/scielo.php?script=sci_arttext\&pid=S0034-

$77011998000200005 \&$ Ing=en\&nrm=iso. Acesso em: 20 ago. 2018.

Bourdieu, Pierre. (2007). A distinção: crítica social do julgamento. Tradução Daniela Kern; Guilherme J. F. Teixeira. São Paulo: Edusp; Porto Alegre: Zouk.

Bourdieu, Pierre. (2002). A dominação masculina. Tradução de Maria Helena Kuhner. (2nd. ed.). Rio de Janeiro: Bertrand Brasil.

Butler, Judith. (2010). Mecanismos psíquicos del poder: teorias sobre la sujeción. Tradução de Jacqueline Cruz. (2nd. ed.). Madrid: Ediciones Cátedra. 
Cardoso, Jéssica Matos, Soares, Alex Sales \& Lima, Carlos Henrique Lucas. (2017). A subversão do gênero e o gênero da subversão. Cadernos de gênero e diversidade, 3(4), 133-144, Out./Dez.

Fanini, Ângela Maria Rubel, Santos, Marcia Lopes dos \& Gnoato, Gilberto. (2017). Cultura da violência, dispositivo do amor-paixão, sexualidade e machismo: uma análise do discurso feminino em relacionamentos conturbados. INTERthesis, Florianópolis, 14(2), 132-151, Mai./Ago.

Farias, Rita de Cássia Pereira. (2009). Conjugalidade e profissão de modelo: projetos conflitantes ou complementares. Cad. Pagu, Campinas, (33), 167-197. Disponível em: http://www.scielo.br/scielo.php?script=sci_arttext\&pid=S0104$83332009000200007 \&$ Ing=en\&nrm=iso. Acesso em: 17 ago. 2016.

Farias, Rita de Cássia Pereira. (2010). Uniforme de trabalho e emancipação feminina: das companhias aéreas à siderurgia. Colóquio de moda. (6), 1-11.

Foucault, Michel. (1982). Microfísica do poder. Rio de Janeiro: Graal.

Geertz, Clifford. (1976). Art as a Cultural System. MLN, 91(6), 1473-1499. Disponível em: www.jstor.org/stable/2907147. Acesso em: 16 jan. 2018.

Geertz, Clifford. (1989). A interpretação das culturas. Rio de Janeiro: LTC.

Goffman, Erving. (1988). Estigma: Notas sobre a manipulação da identidade deteriorada. Tradução de Márcia Bandeira de Mello Leite Nunes. 4. ed. Rio de Janeiro: LTC.

Goldenberg, Mirian. (2006). O corpo como capital: para compreender a cultura brasileira. Arquivos em movimento, 2(2), 115-123. Disponível em: https://revista.eefd.ufrj.br/EEFD/article/viewFile/199/150. Acesso em: 10 de ago. 2018.

Híkiji, Rose Satiko Gitirana. (1998). Antropólogos vão ao cinema: observações sobre a constituição do filme como campo. Cadernos de Campo. São Paulo, VII(7), 91-113. Disponível em: https://doi.org/https://doi.org/10.11606/issn.2316-9133.v7i7p91-113. Acesso em: 16 jun. 2018.

Mauss, Marcel. (2003). Sociologia e antropologia. Tradução de Paulo Neves. São Paulo: Cosac Naify.

López Molina, Sergio Alberto. (2018). El linchamiento de Berenice. Violencia de género e impunidad. Espiral, XXV (72), 151-182.

Novaes, Joana de Vilhena. (2011). Beleza e feiura: corpo feminino e regulação social. In Priore, Mary Lucy Murray Del \& Amantino, Marcia. (Orgs.). História do corpo no Brasil. São Paulo: Unesp.

Paim, Maria Cristina Chimelo \& Strey, Marlene Neves. (2004). Corpos em metamorfose: um breve olhar sobre os corpos na história, e novas configurações de corpos na atualidade. Lecturas: EF y Deportes, 10(79). Disponível em: http://www.efdeportes.com/efd79/corpos.htm. Acesso em: 26 abr. 2018. 
Rezende, Ana Márcia de Almeida \& Silva, Joilson Pereira da. (2017). Violência contra a mulher: representações sociais de adolescentes. INTERthesis, Florianópolis, 15(1), 92-110, Jan./Abr.

Santos, Cecília Macdowell \& Izumino, Wânia Pasinato. (2005). Violência contra as mulheres e violência de gênero: notas sobre estudos feministas no Brasil. Estudios Interdisciplinarios de America Latina y el Caribe, 16(1), 147-164. Disponível em: http://eial.tau.ac.il/index.php/eial/article/view/482. Acesso em: 15 mai. 2018.

Simmel, Georg. (2008). Filosofia da moda e outros escritos. Lisboa: Texto \& Grafia.

Simmel, Georg. (2006). Questões fundamentais da sociologia: indivíduo e sociedade. Rio de Janeiro: Zahar.

Souza, Gilda de Mello e. (1987). O espírito das roupas: a moda no século XIX. São Paulo: Companhia das Letras.

Uma linda mulher. Direção: Garry Marshall. (1990). Produção: Arnon Milchan, Steven Reuther \& Gary W. Goldstein. Intérpretes: Julia Roberts, Richard Gere, Hector Elizondo, Jason Alexander, Ralph Bellamy e outros. Roteiro: Jonathan Frederick Lawton. Música: James Newton Howard. Estados Unidos: Touchstone Pictures. 1 DVD (119 min), color.

Weakland, John H. (1995). Feature films as cultural documents. In Hockings, Paul (Org.). Principles of Visual Anthropology (45-68). New York: De Gruyter.

Wolf, Naomi. (1992). O mito da beleza. Rio de Janeiro: Rocco. 